\title{
Acute normovolemic hemodilution in patients undergoing head and neck surgery: a prospective randomized trial
}

\author{
Yoav Leiser ${ }^{1}$, Michal Barak² ${ }^{2}$, Andrey Kubichka ${ }^{3}$, Micha Peled ${ }^{1}$, Yeshayahu Katz ${ }^{2}$ and Imad Abu el-NaaJ ${ }^{1}$ \\ *Correspondence: m_barak@rambam.health.gov.il \\ 'Departments of Oral and Maxillofacial Surgery, Rambam Health Care Campus, affiliated to the Bruce Rappaport Faculty of Medicine, \\ Technion-Israel Institute of Technology, Haifa, Israel. \\ 2Departments of Anesthesiology Rambam Health Care Campus, affiliated to the Bruce Rappaport Faculty of Medicine, Technion-Israel \\ Institute of Technology, Haifa, Israel. \\ ${ }^{3}$ Department of Anesthesiology Baruch Padeh Medical Center, Tiberius, Israel.
}

\begin{abstract}
Background: Acute normovolemic hemodilution (ANH) is a technique used during anesthesia for major operations, usually to reduce homologous blood transfusion. We studied ANH in large head and neck operations, for which controlled hypotension is required. We selected those procedures since $\mathrm{ANH}$ addresses issues of both decreasing blood pressure and minimizing blood loss

Methods: This is a prospective study of 45 adult patients who underwent elective large maxillofacial resections and orthognathic operations, which duration was predicted to be 3 hours or more. The patients were randomly divided into 2 groups: ANH group (19 patients) and a control group (26 patients). In ANH group one unit of blood was drawn from the patient after the induction of general anesthesia and was returned at the end of the surgery. Target mean blood pressure during the surgery was $30 \%$ below the patient's usual pressure, with a minimum of $50 \mathrm{~mm} \mathrm{Hg}$. Various hemodynamic and laboratory parameters as well as postoperative outcome were monitored.

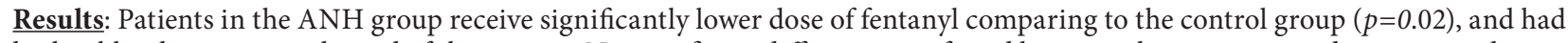
higher blood pressure at the end of the surgery. No significant difference was found between the groups regarding age, gender, weight, ASA class, duration of surgery, usage of hypotensive drugs and blood transfusion during the surgery.

Conclusions: ANH is a safe technique to use in anesthesia for head and neck operations; it facilitates using a smaller dose of fentanyl and assists in resuming higher blood pressure at the end of surgery.
\end{abstract}

Keywords: Anaesthesia, general, anaesthetic technique, hypotensive, surgery, head and neck, normovolemic hemodilution, acute

\section{Introduction}

Controlled hypotension during anesthesia for head and neck surgery has been used for decades to reduce bleeding and improve visibility in the surgical field [1-3]. Over the years, hypotensive anesthesia has been tested and found to be warranted as a routine technique for maxillofacial cancer resections and orthognathic operations. Appropriate patient selection, proper monitoring and adequate intraoperative volume replacement $[4,5]$ are mandatory for this technique to be carried out safely $[1,6]$. Hypotension can be achieved by several means. Most of the anesthetic and analgesic agents have a hypotensive effect, thus as soon as the patient is under general anesthesia, the blood pressure is lower than the baseline. Placing the patient in an anti-Trendelenburg position is useful as well. Various drugs are used to induce hypotension during surgery, such as propranolol, nicardipine, sodium nitroprusside and nitroglycerin [7-9]. Studies that compared drug protocols have failed to find significant difference in outcome $[10,11]$. The goal should be to employ a method or drug which has minimal adverse effects on the patient and is short-acting, since we want to resume the normal blood pressure at the end of the operation.

In this study we tried the technique of acute normovolemic hemodilution (ANH) in patients that underwent major head and neck surgery. ANH is accomplished by drawing a unit of the patient's blood at the beginning of the surgery while administering $500 \mathrm{ml}$ of colloid solution, and returning the autologous blood at the end of the surgery. This technique is used routinely in cardiac surgery and was tried in other major operations as part of blood conservation strategies with the purpose of reducing homologous blood transfusion [12-14]. We hypothesized that ANH could assist in lowering blood pressure during the surgery, thereby reducing the need for hypotensive drugs or other agents that decrease blood pressure. It may also reduce the use of homologous blood transfusion in case of substantial bleeding because the patient bleeds volume of 'diluted' blood.

\section{Patients and methods}

With the approval of our local Ethics Committee (RMB-021209), we conducted a prospective randomized study of adult patients, age 18-80 year old, who were scheduled for an 
elective major head and neck surgery, including: maxillectomy, mandibulectomy, partial glossectomy, modified radical neck dissection, bimaxillary osteotomies and mandibular osteotomy. All the patients signed informed consent to participate in the study. Only patients for whom our hospital's operating room computerized system predicted operation duration of three hours or longer were included in the study. Exclusion criteria were pregnancy, ischemic heart disease, carotid artery disease, hemoglobin below $10 \mathrm{~g} \%$, abnormal preoperative coagulation tests or platelets count, renal insufficiency (preoperative plasma creatinine $>2.0 \mathrm{mg} / \mathrm{dL}$ ), body weight below $50 \mathrm{~kg}$ or above $120 \mathrm{~kg}$, and administration of blood (packed cells) before surgery. Patients who participated in the study were randomly divided into two groups, using computerized software that simulates coin tossing: Group 1-ANH group, Group 2-control group.

\section{Study protocol}

All the patients had standard identical care before, during and after the operation, with the only difference set to be in carrying out ANH. Patients were allowed to drink clear water up to two hours before surgery. Oral premedication included $10 \mathrm{mg}$ diazepam and $10 \mathrm{mg}$ metoclopramide one hour before anesthesia. Upon arrival to the operating room, an intravenous line was placed for fluid and drug administration. The patient was continuously monitored with electrocardiogram, pulse oximeter, end tidal $\mathrm{CO}_{2}$ capnograph, invasive blood pressure and urinary catheter. General anesthesia was induced with $0.03 \mathrm{mg} \mathrm{kg}^{-1}$ midazolam, $0.001 \mathrm{mg} \mathrm{kg}^{-1}$ fentanyl, and 2-5 mg $\mathrm{kg}^{-1}$ propofol followed by $0.1 \mathrm{mg} \mathrm{kg}^{-1}$ vecuronium for muscle relaxation. Sevoflurane was used for maintenance of anesthesia, 2 vol.\% in all patients. Operative blood loss was estimated by counting sponges and measuring the volume collected in the suction bottles. Warm fluids (lactated Ringer's solution) were administered for maintenance (3-5 ml/kg/hour). In addition, each patient received $500 \mathrm{ml}$ of hydroxyethyl starch $6 \%$ in normal saline (HAES 6\%) during the first hour of operation (in patients of ANH group it was when the blood was drawn out).

The target blood pressure during the operation was mean arterial blood pressure (MAP) $30 \%$ below the patient's usual MAP, with a minimum MAP of $50 \mathrm{mmHg}$ [1]. The means for achieving hypotension were: anti-Trendelenburg position $\left(30^{\circ}\right)$, deep sedation ( 2 vol.\% sevoflurane), analgesia (fentanyl up to $20 \mathrm{~g} \mathrm{~kg} \mathrm{k}^{-1}$ ); If those were not effective a drip of $\beta$-blocker (esmolol) was started.

All patients were extubated at the end of the surgery while in the operating room and then transferred to the post anesthesia care unit (PACU) where they were monitored for 3 hours.

\section{Acute normovolemic hemodilution}

A standard blood unit (300gr) was drawn from the patient that was assigned to the ANH group. The blood was taken after the completion of the induction of general anesthesia.
At that time $500 \mathrm{ml}$ of HAES $6 \%$ was transfused. Afterwards, during the surgery, if the patient required blood along the operation, first his/her blood was administered and after wards homologous blood. The triggers for blood transfusion was hematocrite below $22 \%$. In the case there was no need for blood transfusion, the patient's blood was returned at the end of surgery.

The mean blood pressure (MBP), heart rate (HR) and hematocrite $(\mathrm{HT})$ were recorded three times during the anesthesia: at the beginning of the induction (MBP1, HR1, $\mathrm{HT} 1)$, one hour later (MBP2, HR2, HT2) and at the end of the surgery (for patients in $\mathrm{ANH}$ group it was after returning the autologous blood unit) (MBP3, HR3, HT3).

Data collected for each patient were demographic and medical information, surgical and anesthetic information, events during and after surgery and blood tests. Anesthesiologists were not blinded to the ANH procedure, and the same anesthesiologist who managed the patient during surgery collected the data.

\section{Statistical analysis}

Sample size was determined assuming a difference of $25 \%$ in the dosage of hypotensive drugs or fentanyl. The estimated SD within the control group was 3.6, with alpha error $=0.05$ and the beta error $=0.1$.

Data from patients' records was analyzed with a commercial statistical software package (Statistica 6.0, StatSoft, Tulsa, OK). Frequencies were compared using Pearson's chi square test. Continuous variables were compared using analysis of variance, with repeated measures where applicable. Homogeneity of variance was tested with Levene's test.

\section{Results}

Forty five patients were included in the study. Three patients were excluded: two because the body weight was below 50 $\mathrm{kg}$ and one because of ischemic heart disease. In the ANH group there were 19 patients, in the control group there were 26 patients. The demographic, pre- and intra-operative data is summarized in (Table 1). The types of operation are in (Table 2).

Patients in ANH group receive significantly lower dose of fentanyl $\left(\mu \mathrm{g} \mathrm{kg}^{-1}\right)$ comparing to the control group ( $p=0.02$ ).

Mean blood pressure was similar between the groups in MBP1 and MBP2. The mean blood pressure was significantly higher in ANH group at the end of the surgery (MBP3) $p=0.001$. The mean blood pressure variation is shown in (Figure 1).

The heart rate was similar in both groups during the surgery (Figure 2). There was significant difference between the groups in HT1 $(p<0.01)$ and HT3 $(p=0.049)$ although not in $\mathrm{HT} 2$ (Figure 3).

In the PACU no patient required treatment for high or low blood pressure and no one received blood. The postoperative course was uneventful for all the patients and there was no mortality. There was no significant difference between the groups regarding the length of hospital stay. 
Table 1. Demographic, pre- and intra-operative data of the patients that participated in the study.

\begin{tabular}{|c|c|c|c|}
\hline & $\begin{array}{c}\text { ANH Group } \\
(\mathrm{N}=19, \text { mean } \pm \mathrm{SD})\end{array}$ & $\begin{array}{c}\text { Control Group } \\
(\mathrm{N}=26, \text { mean } \pm \mathrm{SD})\end{array}$ & $P$ value \\
\hline Age (years) & $47( \pm 16.5)$ & $37.1( \pm 18.9)$ & NS \\
\hline Gender: male/female & $10 / 9$ & $14 / 12$ & NS \\
\hline Weight (kg) & $76.1( \pm 18)$ & $65.5( \pm 11.8)$ & NS \\
\hline BMI & $25.7( \pm 5.6)$ & $23.4( \pm 3.6)$ & NS \\
\hline ASA class: $1 / 2 / 3$ & $8 / 11 / 0$ & $11 / 13 / 2$ & NS \\
\hline Patients with hypertension & $6(32 \%)$ & $6(23 \%)$ & NS \\
\hline Hemoglobin (baseline) $\mathrm{g} \%{ }^{*}$ & $13.7( \pm 1.7)$ & $13( \pm 1.3)$ & NS \\
\hline $\begin{array}{l}\text { Intra-operative Data } \\
\text { Duration of surgery }(\mathrm{h}) \\
\text { EBL }(\mathrm{ml}) \\
\text { Urinary output (ml/Kg/hour) }\end{array}$ & $\begin{array}{c}4.1( \pm 0.7) \\
302( \pm 140) \\
0.2( \pm 0.1)\end{array}$ & $\begin{array}{c}4.4( \pm 1.3) \\
314( \pm 198) \\
0.3( \pm 0.1)\end{array}$ & $\begin{array}{l}\text { NS } \\
\text { NS } \\
\text { NS }\end{array}$ \\
\hline Fentanyl ( $\mu \mathrm{g} / \mathrm{kg})$ & $11( \pm 3)$ & $13.4( \pm 3.6)$ & $P=0.02$ \\
\hline $\begin{array}{l}\text { Number of patients that } \\
\text { received } \beta \text {-blocker }\end{array}$ & $2(10 \%)$ & $3(11 \%)$ & NS \\
\hline $\begin{array}{l}\text { Number of patients that } \\
\text { required blood transfusion }\end{array}$ & $1(5 \%)$ & $2(8 \%)$ & NS \\
\hline
\end{tabular}

$\mathrm{N}=$ number of patients; $\mathrm{NS}=$ not significant; $\mathrm{SD}=$ standard deviation; $\mathrm{BMI}=$ body mass index; $\mathrm{ASA}=$ American Society of Anesthesiologists; EBL= estimated blood loss; ${ }^{\star}$ Normal range is 12.0-16.0 g\%.

Table 2. Types of operations.

\begin{tabular}{lcc}
\hline Type of Operation & $\begin{array}{c}\text { ANH Group } \\
(\mathbf{N}=\mathbf{1 9})\end{array}$ & $\begin{array}{c}\text { Control Group } \\
\text { (N=26) }\end{array}$ \\
\hline Partial glossectomy + radical neck dissection & 4 & 3 \\
Partial mandibulectomy + radical neck dissection & 2 & 4 \\
Parotidectomy + radical neck dissection & 0 & 2 \\
Maxillectomy & 2 & 0 \\
Radical orbitomaxillectomy & 2 & 1 \\
Segmental osteoplasty of maxilla & 4 & 2 \\
Osteoplasty of mandibule & 1 & 3 \\
Reconstruction of mandibular bone & 2 & 4 \\
Bone graft to the orbit & 1 & 1 \\
Bone graft to the maxilla & 0 & 2 \\
Open reduction of Mandibule & 1 & 1 \\
Bilateral parotidectomy & 0 & 1 \\
Internal fixation of face bone & 0 & 2 \\
\hline
\end{tabular}

\section{Discussion}

The main finding of this study is that $\mathrm{ANH}$, when performed during large head and neck operations, results in reducing the dose of fentanyl administered to the patients.

We believe that in the ANH group the target MBP was reached earlier, while in the control group the anesthesiologists continued to administer fentanyl in order to reach the target MBP. Although fentanyl is not the drug of choice for reducing blood pressure, it may be given assuming that the high blood pressure is due to pain. It is important to remember that the dosage of fentanyl given to the ANH group was not low, with a mean of $11( \pm 3) \mu \mathrm{g} / \mathrm{kg}$, it is, however; significantly lower than that given to the control group. The reduced dose of

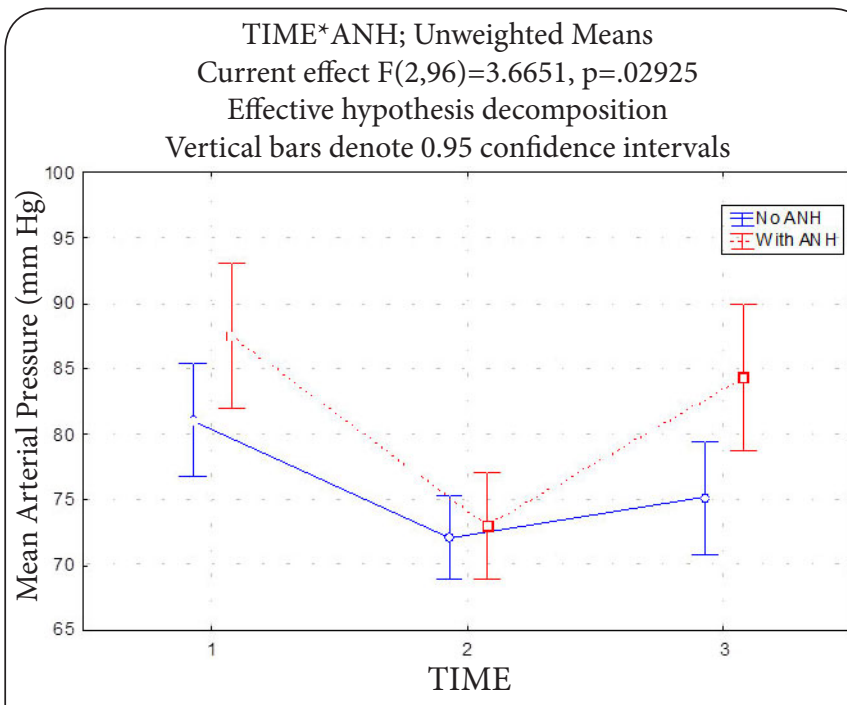

Figure 1. Mean blood pressure variation during the operation.

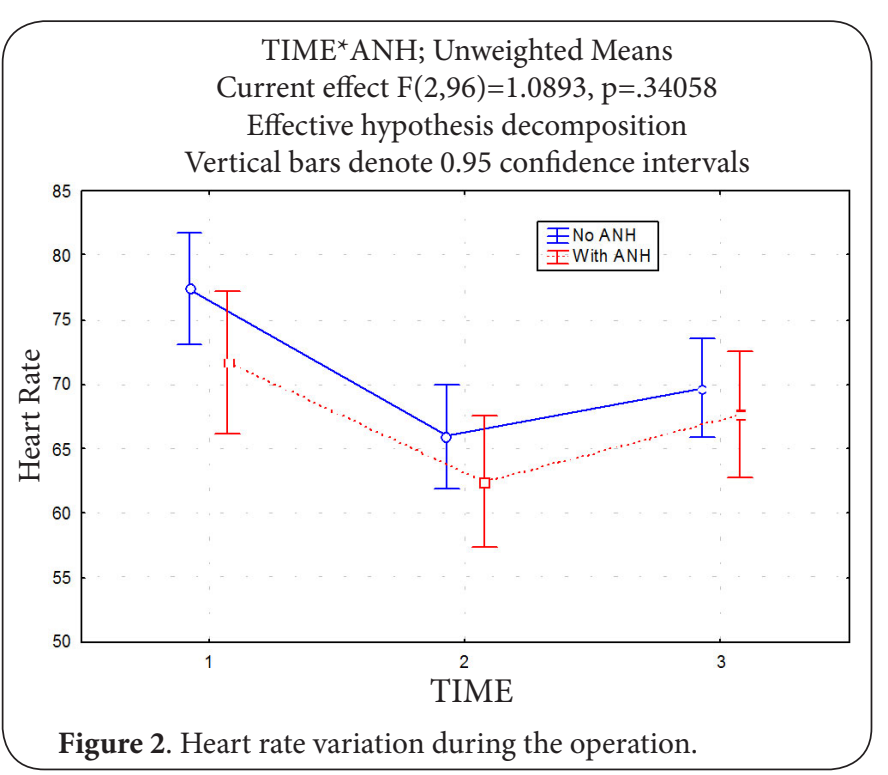

fentanyl is beneficial to the patient since it may lead to fewer postoperative opioid side effects, such as nausea and vomiting, or respiratory depression $[15,16]$. These side effects can also prolong the PACU stay. Indeed, it could be argued that lower fentanyl doze could have been achieved by other means of controlled hypotension, such as sodium nitropruside.

An additional finding in the study was that patients in the ANH group resumed higher mean blood pressure at the end of the procedure comparing to the control group. This may be attributed to the fact that the study group had the enhancement of their autologous blood at the end of the surgery, while the patients in the control group had no 'boost' at that time. In addition, unlike the effect of some 


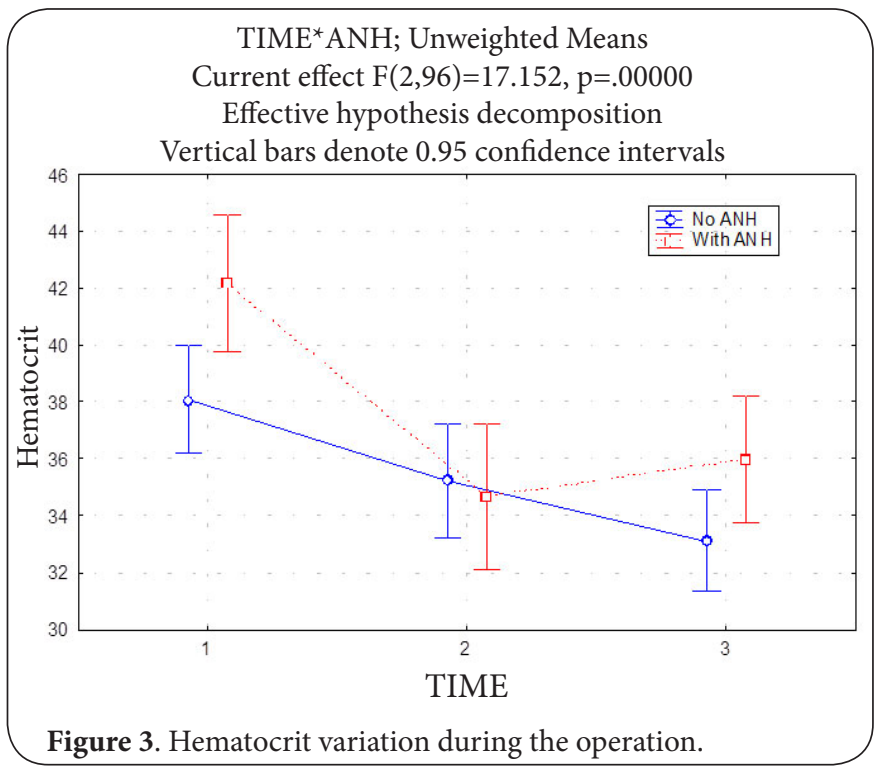

drugs used to reduce blood pressure, the ANH effect is fully reversed when the autologous blood is returned to the patient. Furthermore, the duration of ANH effect is easily and entirely regulated, because the blood can be administered to the patient when required. We found $\mathrm{ANH}$, when used in selected patient population, to be superior to other means of lowering blood pressure during major maxillofacial surgery, since it accentuates the desired effect of low blood pressure during the surgery and increased blood pressure at its end.

ANH has been known for decades, and is performed routinely during open heart surgery, when a cardiopulmonary bypass machine is used [17]. Its advantages in that setting include supplying the patient with his/her own blood unit that has not been exposed to cardiopulmonary machine damage. Recently, the indications to use ANH have been expanding and $\mathrm{ANH}$ is used in major liver resections, radical prostatectomy, spine operations and during brain tumor resection $[14,18,19]$. Consequently, ANH is now considered to be an element of blood conservation strategy, reducing the need for homologous blood transfusion during surgery $[20,21]$. Other effects, not so favorable, are the hemodynamic changes that occur during $\mathrm{ANH}$, including decreased cardiac output $[22,23]$. There are risks in using ANH in opposed to using vasoactive drugs to control the blood pressure. The oxygen carrying capacity of the patient's 'diluted' blood is reduced. Often the hemodilution process results in increased heart rate, both effects may lead to cardiac ischemia.

ANH was studied previously in maxillofacial surgery by Habler et al., [24]. They focused on the difference in intraoperative allogeneic blood transfusion between the ANH patients and the control group and found ANH to be a practicable, safe and economic blood conservation technique. The authors did not refer to other aspects of ANH during anesthesia. Altogether it is important to note that ANH is not suitable in every case and patient's condition should be considered carefully before it is used.

The main weakness of our study is the fact that the anesthesiologists who managed the patients and collected data were not blind to the group segmentation and, therefore, bias may have resulted. Another limitation of the study was the difference in the baseline data of hematocrit (HT1) between the two groups. That difference was unknown to the researchers until the statistical analysis was completed. In addition, the random allocation of the patients resulted in 19 patients in one group and 26 patients in the other group. Regarding blood loss during surgery, in our study a relatively small number of patients required homologous blood transfusions, thus a comparison of blood loss between the ANH and the control groups was not meaningful.

In this study, when ANH was performed during large head and neck operations, we found that patients received significantly lower dose of fentanyl and resumed higher MBP at the end of surgery.

\section{Competing interests}

The authors declare that they have no competing interests.

Authors' contributions

\begin{tabular}{|l|c|c|c|c|c|c|}
\hline Authors' contributions & YL & MB & AK & MP & YK & IA \\
\hline Research concept and design & $\checkmark$ & $\checkmark$ & -- & -- & -- & $\checkmark$ \\
\hline Collection and/or assembly of data & -- & $\checkmark$ & $\checkmark$ & -- & -- & -- \\
\hline Data analysis and interpretation & $\checkmark$ & $\checkmark$ & $\checkmark$ & -- & -- & $\checkmark$ \\
\hline Writing the article & $\checkmark$ & $\checkmark$ & -- & $\checkmark$ & -- & $\checkmark$ \\
\hline Critical revision of the article & $\checkmark$ & $\checkmark$ & -- & -- & -- & $\checkmark$ \\
\hline Final approval of article & $\checkmark$ & $\checkmark$ & $\checkmark$ & $\checkmark$ & $\checkmark$ & $\checkmark$ \\
\hline Statistical analysis & -- & -- & $\checkmark$ & -- & -- & -- \\
\hline
\end{tabular}

Publication history

EIC: D. John Doyle, Case Western Reserve University, USA. Received: 29-Oct-2013 Revised: 18-Nov-2013

Accepted: 23-Nov-2013 Published: 05-Dec-2013

\section{References}

1. Rodrigo C. Induced hypotension during anesthesia with special reference to orthognathic surgery. Anesth Prog. 1995; 42:41-58. | PubMed Abstract | PubMed Full Text

2. Thomas AA and Rittersma J. Anaesthetic experiences in orthodontic surgery. J Maxillofac Surg. 1978; 6:204-6. | Article I PubMed

3. Varol $A, B a s a S$ and Ozturk $S$. The role of controlled hypotension upon transfusion requirement during maxillary downfracture in double-jaw surgery. J Craniomaxillofac Surg. 2010; 38:345-9. | Article | PubMed

4. Chappell D, Jacob M, Hofmann-Kiefer K, Conzen P and Rehm M. A rational approach to perioperative fluid management. Anesthesiology. 2008; 109:723-40. | Article | PubMed

5. Jacob M, Chappell D and Rehm M. Clinical update: perioperative fluid management. Lancet. 2007; 369:1984-6. | Article | PubMed

6. Choi WS and Samman N. Risks and benefits of deliberate hypotension in anaesthesia: a systematic review. Int J Oral Maxillofac Surg. 2008; 37:687-703. | Article | PubMed 
7. Apipan B and Rummasak D. Efficacy and safety of oral propranolol premedication to reduce reflex tachycardia during hypotensive anesthesia with sodium nitroprusside in orthognathic surgery: a double-blind randomized clinical trial. J Oral Maxillofac Surg. 2010; 68:120-4. | Article | PubMed

8. Yoshikawa F, Kohase $\mathrm{H}$, Umino $\mathrm{M}$ and Fukayama H. Blood loss and endocrine responses in hypotensive anaesthesia with sodium nitroprusside and nitroglycerin for mandibular osteotomy. Int J Oral Maxillofac Surg. 2009; 38:1159-64. | Article | PubMed

9. Kim JE, Lee JS, Kim MK, Kim SH and Kim JY. Nicardipine Infusion for Hypotensive Anesthesia During Orthognathic Surgery Has Protective Effect on Renal Function. J Oral Maxillofac Surg. 2013. | Article | PubMed

10. Rossi A, Falzetti G, Donati A, Orsetti G and Pelaia P. Desflurane versus sevoflurane to reduce blood loss in maxillofacial surgery. J Oral Maxillofac Surg. 2010; 68:1007-12. | Article | PubMed

11. Farah GJ, de Moraes M, Filho LI, Pavan AJ, Camarini ET, Previdelli IT and Coelho L. Induced hypotension in orthognathic surgery: a comparative study of 2 pharmacological protocols. J Oral Maxillofac Surg. 2008; 66:2261-9. | Article | PubMed

12. Casati V, Speziali G, D’Alessandro C, Cianchi C, Antonietta Grasso $\mathrm{M}$, Spagnolo $S$ and Sandrelli L. Intraoperative low-volume acute normovolemic hemodilution in adult open-heart surgery. Anesthesiology. 2002; 97:367-73. | Article | PubMed

13. Oppitz PP and Stefani MA. Acute normovolemic hemodilution is safe in neurosurgery. World Neurosurg. 2013; 79:719-24. | Article | PubMed

14. Jarnagin WR, Gonen M, Maithel SK, Fong Y, D'Angelica MI, Dematteo RP, Grant F, Wuest D, Kundu K, Blumgart LH and Fischer M. A prospective randomized trial of acute normovolemic hemodilution compared to standard intraoperative management in patients undergoing major hepatic resection. Ann Surg. 2008; 248:360-9. | Article | PubMed

15. Watcha MF and White PF. Postoperative nausea and vomiting. Its etiology, treatment, and prevention. Anesthesiology. 1992; 77:162-84. | Article I PubMed

16. Coluzzi F, Rocco A, Mandatori I and Mattia C. Non-analgesic effects of opioids: opioid-induced nausea and vomiting: mechanisms and strategies for their limitation. Curr Pharm Des. 2012; 18:6043-52. | Article I PubMed

17. Scott WJ, Rode R, Castlemain B, Kessler R, Follis F, Pett SB and Wernly JA. Efficacy, complications, and cost of a comprehensive blood conservation program for cardiac operations. J Thorac Cardiovasc Surg. 1992; 103:1001-6. | Article | PubMed

18. Daif AA, Hassan YM, Ghareeb NA, Othman MM and Mohamed SA Cerebral effect of acute normovolemic hemodilution during brain tumor resection. J Neurosurg Anesthesiol. 2012; 24:19-24. | Article | PubMed

19. Naqash IA, Draboo MA, Lone AQ, Nengroo SH, Kirmani A and Bhat AR. Evaluation of acute normovolemic hemodilution and autotransfusion in neurosurgical patients undergoing excision of intracranial meningioma. J Anaesthesiol Clin Pharmacol. 2011; 27:54-8. | Article | PubMed Abstract | PubMed Full Text

20. Bennett J, Haynes S, Torella F, Grainger H and McCollum C. Acute normovolemic hemodilution in moderate blood loss surgery: a randomized controlled trial. Transfusion. 2006; 46:1097-103. | Article | PubMed

21. Shander A and Rijhwani TS. Acute normovolemic hemodilution. Transfusion. 2004; 44:26S-34S. | Article | PubMed

22. Kungys G, Rose DD and Fleming NW. Stroke volume variation during acute normovolemic hemodilution. Anesth Analg. 2009; 109:1823-30. | Article | PubMed

23. Licker M, Ellenberger C, Sierra J, Christenson J, Diaper J and Morel D. Cardiovascular response to acute normovolemic hemodilution in patients with coronary artery diseases: Assessment with transesophageal echocardiography. Crit Care Med. 2005; 33:591-7. I Article | PubMed

24. Habler O, Schwenzer K, Zimmer K, Prager M, Konig U, Oppenrieder K,
Pape A, Steinkraus E, Reither A, Buchrot A and Zwissler B. Effects of standardized acute normovolemic hemodilution on intraoperative allogeneic blood transfusion in patients undergoing major maxillofacial surgery. Int J Oral Maxillofac Surg. 2004; 33:467-75. | Article | PubMed

\section{Citation:}

Leiser Y, Barak M, Kubichka A, Peled M, Katz Y and Abu el-NaaJ I. Acute normovolemic hemodilution in patients undergoing head and neck surgery: a prospective randomized trial. J Anesthesiol Clin Sci. 2013; 2:30. http://dx.doi.org/10.7243/2049-9752-2-30 